\title{
INTERVIEW: Know thy \\ neighbours-Asian Australian \\ Studies helps you know thyself
}

Edition 5, 2021

Dr Tseen Khoo \& Dr Mridula Nath Chakraborty

DOI: 10.37839/MAR2652-550X5.22

The unfolding consequences of the COVID-19 pandemic are particularly salient for Asian Australian Studies and its communities. These include heightened levels of anti-Asian abuse, a drastic fall in international student numbers and subsequent tertiary sector decimation, austere times for creative arts and community work, and the fraught politics of essential workers in low-paid jobs.

COVID-19 did not create any of these issues but they have been exacerbated during the pandemic, along with societal inequities more broadly. These are significant aspects of the impact that COVID-19 is having on Australia's complex social and cultural relationship with Asia and its own Asian Australian communities.

Dr Tseen Khoo at La Trobe University in Melbourne is the founding convenor of the Asian Australian Studies Research Network (AASRN), a peak scholarly group that examines critical issues of society, politics and culture relating to the diverse Asian diaspora in Australia.

Dr Mridula Nath Chakraborty, at Monash University in Melbourne, is the current national convenor of the AASRN, with a background in postcolonial theory, diaspora studies and multiculturalism.

They spoke with the Managing Editor of Melbourne Asia Review, Cathy Harper. 


\section{What are some of the key developments that have influenced the study of Asian communities and cultures in Australia?}

TK: Asian Australian Studies has established itself more visibly as a scholarly field over the past few decades. This is not to say that work on Asian Australian communities was not in evidence before that, and when the AASRN was formally founded in 2006, it was a chance to coalesce the area's momentum and gave Asian Australian Studies scholars the chance to more actively collaborate. I think a major element of the area has always been establishing space for those of Asian heritage in Australia to think, create, and research without always having to justify the validity of our field of study. Attention and sustained work into these topics has fluctuated and they have gained particular prominence at times when there is significant antiAsian discourse, like in the 1980s when historian Geoffrey Blainey warned against the 'Asianisation' of Australia, again in the 1990s with the political rise of Pauline Hanson and One Nation, and of course now with the steep increase in racial abuse against those of Asian heritage. It's certainly not a case of these being the only points in time that Asian Australian Studies are salient; more that these are the times when the paucity of understanding of Asian Australian experiences and lives comes to the fore.

Asian Studies and Australian Studies are two broad interdisciplinary fields that were already established and having Asian Australian Studies 'misunderstood' as one or the other is a regular thing-there are certainly overlaps and complementary areas of interest and Asian Australian Studies has more in common with research focused on diasporic Asian communities living in contexts where they are minorities. Thinking here of the influence, and confluence, of Asian North American Studies (Canada/USA), and Asian New Zealand studies. You've lived more of a diasporic Asian life than me, Mridula, having been in Canada for years as well, do you think this is accurate?

MNC: Yes, certainly that is correct, Tseen. I think Asian Australian Studies can be seen as part of, and participant in, the larger body of global scholarship on diaspora 
theory, and migration research that emerged in the wake of a globalised and transnational world. These studies, that explore the existences and expressions of diasporic Asian communities in Anglophone countries, have been flourishing for the last 30 years at least in Australia. In Britain, Canada and the United States, these identity-based movements have had an older lineage, because of other historical contingencies. Of course, Asian people have marked and populated the landscape of Australia since the birth of the nation: their stories provide part of an alternative narrative to the dominant one of white settler colonialism, along with Indigenous narratives. In the last two decades, there has been a gathering of momentum in properly uncovering the two-centuries old Asian presence in Australia, and to bring to the fore the rich and layered Asian genealogies that have contributed to the making of contemporary Australia. For example, long vilified as Yellow Peril, or Fear of a Brown Planet, the spectre of always-under-the-surface racism against Asian Australians (a mainstream narrative that deems them the alien 'outsiders' to the body politic) is now being countered by the artistic and academic mappings of early Asian presence in Australia. Works such as Wong Shee Ping's The Poison of Polygamy (serialised in 1909-1910, and translated in 2019 by Michael Williams) and Samia Khatun's Australianama: the South Asian Odyssey in Australia are providing the much required, and renewed, rider to the contentious debate over British colonialism in Australia known as the History Wars. In the face of monumental geopolitical shifts of power being predicted (and already happening) in the Asian Century, Asian Australian Studies both make a claim to legitimacy within the nation state, and challenge its foundational pieties. They straddle the Blak/White dichotomy in Australia and show the close interactions between the First Peoples and Asian arrivals. And one necessary clarification: while Asian Australians trace their stories of settlement from the Asian continent north to us, Asian Australian Studies are conducted by any scholars, irrespective of their identity, who are interested in showcasing the truly diverse face of Australia, so to speak, with its variegated histories. 


\section{What effect do you think COVID-induced inwardness and self- preservation will have on Australia's national identity?}

MNC: In a recent article, George Megalogenis explores the idea of underwogs, a term he uses to describe the extraordinary successes of Australia's post-World War II migration program, that saw economic contributions from first generations of European migrants, followed by educational and professional excellence of the second generation. He then strikes a note of caution that current self-selecting patterns of Australia's contemporary migration program prioritise an industrial and service economy, that mitigates against any shared 'Australian' values. I think he is right in the first instance and wrong in the second. To begin with, the much-vaunted Australian values of a 'fair-go' and egalitarian society have come under considerable scrutiny in recent years and have been shown to be myths propagated by the privileged to preserve themselves at the cost of others. In particular, populations that are 'otherised' are often under pressure to buy into such aspirational idealisms that then become the very tools by which multicultural assumptions can be managed, such as the idea of the model minority. Second, in the age of transnationalism, any such assumed values have to necessarily stand the test of global cultural waves that enter the space of the national; in the case of Australia, this necessarily means that the normative identity of Australia as 'white' has to face a fundamental challenge. It is in this space that Asian Australian Studies provides a unique platform to both demonstrate the intrinsically multicultural face of Australia and undertake the essential research to work against such inwardness that is damaging to the interests of a thriving collectivity. If Australia is indeed serious about its positioning in the world and in the Asian region, then it must actively persuade its own constituents that the plural 'we' is ready to embrace our national identity as diverse.

TK: Yes, I'd agree with this. I think the Australian public conversation has a relatively parochial and short-term perspective on many things, especially when it comes to conceiving of a diverse national community that doesn't centre AngloAustralians and their experiences. It seems that over the last couple of decades 
diversity has often become perceived to be less of a positive element in Australian society, and more a divisive and 'trouble-making' one. This is certainly the case if you listen to our current political leaders. It has been interesting to see the ways in which COVID-related crises, like various quarantine failures and resulting clusters in particular suburbs, become judgements about some cultural groups and the ways they may or may not 'follow the rules'. I'm thinking here of the representation of the cluster in the northern Melbourne suburb of Broadmeadows that generated fears of an Islamaphobic response. The global response to how well Australia has handled community-transmitted COVID outbreaks portrays us as a fairly compliant population that's focused on 'greater good' outcomes, and our government as one that will do what it takes to get the pandemic under control.

\section{How has it affected Asian communities in Australia, particularly international students and others on temporary visas?}

MNC: Apart from the socio-economic fallout of short-sighted, profit-oriented concerns of the gig economy and the educational sector, Australia's biggest loss in targeting the Asian community in the COVID-19 scenario has come at the cost of its own national fabric. The overwhelming conversation in our public sphere has been about the impact of the loss of international student revenue to the coffers: Australia has lost sight of the human and humane cost through the use of such mercenary language that treats international students as capital and 'cash cows'. Connected to this are the recent outrages against gig-economy workers like the fruit-picking and food-delivery industries, much of which are serviced by international students and the cheap labour of temporary workers. However, the brunt of these policy decisions have been experienced by Australia's home-grown Asian communities, whose very legitimacy as Australian citizens has been questioned. So, both on the domestic as well as international front, the fault lines of Australia's dominant, exclusionary and politicised self-visualisation as Anglo-Celtic and of European-descent has played out in terms of ramping up the already existing racial discrimination in our society, in order to 'otherise' and subject to further horrific abuse those who are deemed to not belong. 
TK: I think it has been clear that the government made a big misstep with the way it dealt with the stranded international students in the immediate aftermath of COVID restrictions and border closures. Even pre-COVID, institutions have struggled consistently when it comes to offering their international students sufficient support services and connection points once they are in Australia. As Mridula points out, Australia has long treated international students as 'cash cows'. So, I wouldn't say that failing to support international students is a new thing, but the crass way our government dealt with the growing COVID issue emphasised once again how these students-and anyone who is not a citizen-are excluded from being considered part of the Australian community, even if they're taxpayers. They were basically told to 'go home'.

Being told to 'go home' is unfortunately nothing new for many Asian Australians. It's one of the common ways that Asian individuals and communities are made to feel they don't belong here. The escalation of anti-Asian abuse and discrimination is an active area of research for quite a few scholars, and the Scanlon Foundation recently released its 2020 report, which stated that there is a 'relatively high level of negative opinion' towards Asian Australians.

\section{Tseen, you've written in the last few years about the danger of 'normalisation of political racism'. What is meant by this and what effect is it having?}

TK: That phrase, 'normalisation of political racism', comes from a piece on Asian Australian mobilities that I co-authored with my colleague Jen Tsen Kwok, whose research focuses on Asian Australians and the culture of politics. It means the acceptance of differentiated treatment of Australian citizens within the nation, often under the guise of 'free speech'. I'm thinking here of comments by Australian Members of Parliament that are suspicious of, or vilify, particular cultural groups (like Senior Liberal Eric Abetz's questioning of Chinese Australians during a Senate Committee hearing). The ongoing, often acrid debates around CCP influence in Australia is a good example of an issue that has very clear, often negative effects on 
local Asian Australian communities. The knee-jerk accusations of being a member of the CCP shuts down possibilities for more complex views of the situation and what the often vociferous anti-China stances result in is abuse of Asian Australians for not immediately joining in. This erases the experiences and opinions of various Asian Australian groups (which differ quite markedly! Because 'Asians' are so often viewed as a monolithic group with one perspective). To me, it boils down to the perception that some groups belong more than others, and Asian Australian communities being too often viewed as being contingent members of the nation. The effect of CCP politics and actors in Australia is of concern, as with any foreign power's undue influence in Australia. Many colleagues have expressed strong criticism of these dynamics, with careful awareness of the potential for inflammatory 'Yellow Peril' rhetoric.

MNC: I think 'normalisation of political racism is a very important term that Tseen and Jen have used to explain what is an increasingly divisive way of understanding Australia's national polity, deriving of course from the age-old White Australia Policy. When I think of the difference between my decade-long stint in Canada and now a dozen years in Australia, the stark contrast seems, to me, to be that despite Australia being visibly and culturally much more Asian at the street level, due to long-standing migration patterns and proximity to Asia, our political language remains entrenched in an exclusionary imagined community tied to the apron strings of colonisation and the empire. The damaging political rhetoric that regularly rears its head, not just from fringe parties, but sometimes even the two major ones, is unnecessarily vituperative and flies in the face of the how the 'common' Australian might already be living and experiencing, with neighbours of every different hue and colour. As the Federal Labor MP for Gellibrand, Tim Watt's explained in his recent book, The Golden Country: Australia's Changing Identity (2019), Australia's current securitised immigration policies lead to an atmosphere of creating 'us' and 'them' categories, instead of bringing people together for nation building. These entrenched attitudes, coming from the top down, also betray the kind of insular mentality that Donald Horne warned us against in The Lucky Country (1964). 
The chorus of voices from academics, businesses, corporates, institutions now drawing attention to the systemic inequalities that are preventing Asian Australians from achieving their full potential and contributing to Australia's cultural, human and economic capital, should be a matter of national concern. Unfortunately, political racism drowns out the progressive politics that might shape an Australia to come, an Australia of the future, an Australia that truly acknowledges its constitutive diversity and makes it possible for that to flourish and flower.

Image credit: Steel Wool/Flickr. 